\title{
10. Mainstreaming HIV and AIDS in the Law and Justice Sector
}

\author{
IAN PATRICK
}

The HIV epidemic in Papua New Guinea (PNG) demands effective responses from national leaders and public sector organisations charged with maintaining public health and more broadly promoting citizen welfare. These challenges are heightened in a complex sector such as law and justice - comprising six major agencies and two offices. ${ }^{1}$

This chapter explores opportunities and challenges for advancing a 'mainstreaming' response to HIV in the law and justice sector. ${ }^{2}$ Mainstreaming requires an organisation to adapt its core business to address HIV and AIDS. This approach is equally applicable to public sector, private sector and civil society organisations. Mainstreaming is a key strategy in AusAID's support for strengthening coordination and capacity within partner countries for national responses to HIV (AusAID 2009, 23; AusAID 2006, 18, 21, 23).

What does a mainstreaming approach in the law and justice sector involve? How can development partners help this process? Two case studies concerning HIV initiatives within AusAID-suported law and justice projects will be discussed here. Although these initiatives were not designed as 'mainstreaming' measures they illuminate lessons for a mainstreaming approach. These initiatives were incorporated within the Royal Papua New Guinea Constabulary Development Project Phase III (2000-2005) (see also McLeod and Macintyre this volume), and the Correctional Services Development Project Phase II (2000-2003) and have informed LJSP's continuing response to HIV and AIDS.

\footnotetext{
1 Department of Justice and Attorney General, National Judicial Staff Services, Ombudsman Commission, Royal Papua New Guinea Constabulary, Correctional Services, Magisterial Services, Office of the Public Prosecutor and Office of the Public Solicitor.

2 This chapter draws on a review (Patrick 2005) conducted for AusAID in the period February to April 2005 that examined eight programs/projects supported by AusAID that had HIV/AIDS elements. These projects were located across a range of sectors including law and justice. Both of the case studies included in this paper were examined in the review. The review involved examination of AusAID and program/project documentation, and conduct of a wide range of interviews with stakeholders across government departments, managing contractors, AusAID, NHASP and NACS. The results of these interviews are used here.
} 
Civic Insecurity

\section{Notions of Mainstreaming}

Mainstreaming is 'a process that enables development actors to address the causes and effects of HIV/AIDS in an effective and sustained manner, both through their usual work and their workplace' (UNAIDS 2004, 4). It might, for example, involve an agriculture ministry adapting its extension work to focus on AIDS-affected families; or the judicial system introducing new codes of practice to protect the rights of people infected or affected by HIV or AIDS.

Throughout the 1990s, the limitations of a uni-focused, health-led response, typically delivered within a medical context, became increasingly clear. This led to the recognition that a universal, multisectoral approach to the epidemic was needed, involving many sectors such as education, law and justice, and infrastructure (United Nations 2001; UNAIDS and World Bank 2001; UNAIDS 2003, 2004). While a multisectoral approach retains specific HIV interventions, such as counselling and treatment, it also includes the adoption of a mainstreamed response that fundamentally requires sectors and their constituent organisations to adapt their core business to address HIV.

'Mainstreaming' challenges development actors to broaden their understanding and analysis of HIV and AIDS, including how they themselves can contribute, usually inadvertently, to HIV's spread. All sectors and their constituent organisations must answer the following questions:

- How might they be contributing to the spread of HIV?

- In what areas does their sector have a comparative advantage for limiting HIV's spread and mitigating the epidemic's impact?

- How is the epidemic likely to affect the goals, objectives and programs of the sector/organization?

- What context-specific actions, backed by sufficient resources, are required to address identified areas (UNAIDS and GTZ 2002, 5; SDC 2004,19)?

\section{Good Practice in Mainstreaming}

Good practice principles for HIV mainstreaming (eg. Wilkins and Vasani 2002; UNDP 2002; UNAIDS and GTZ 2002; Elsey and Kutengule 2003; UNAIDS 2004; SDC 2004) suggest that effective mainstreaming needs to

- be strategic and coordinated: initiatives in each sector must clearly link to a national HIV strategy, with active coordination between national/ sectoral coordinating bodies and implementing organisations. Partnerships 
for sharing knowledge and resources should also be developed and gaps in service provision filled.

- be based on a sector's or organisation's comparative advantage: initiatives should follow an analysis identifying areas of sectoral/organisational responsibility and how the most efficient and effective response can be made.

- occur in both the internal and external domains: for example, through an organisation both training its staff and working externally with clients/ beneficiaries in order to reduce risk and vulnerability to HIV.

- promote appropriate capacity-building: initiatives need to build the necessary commitment, knowledge and skills required for mainstreaming amongst staff and policy makers. Ideally, initiatives should strengthen existing institutional and community structures, rather than create new structures.

- address other cross-cutting issues: HIV responses need particularly to focus on and respond to issues of gender, participation and sustainability, because they critically inter-relate with HIV and the effectiveness of initiatives.

The above principles suggest that initiatives need to extend well beyond 'awareness raising' for staff which is the 'classic', superficial and limited response (Wilkins and Vasani 2002). Elsey and Kutengule (2003), for example, state that the range of organisational responses may include:

- putting in place policies and practices that protect staff from vulnerability to infection and support staff who are living with HIV and its impacts; ensure that training and recruitment consider future staff depletion rates; and consider the disruption caused by increased morbidity and mortality.

- refocusing the organisation's work to ensure those infected and affected by HIV are included and able to benefit from the organisation's activities.

- ensuring that an organisation's activities do not increase the vulnerability to HIV and other STIs in the communities with which it works, or undermine community options for coping with the epidemic's effects.

\section{A Shift to a Multisectoral Approach and Mainstreaming}

The two initiatives examined here were attempts to build organisational commitment and response to HIV within two major AusAID projects that were designed during the late 1990s and originally included no HIV provisions. Rather, responses were added during implementation, due to concern about 
PNG's worsening epidemic and a new commitment to a multisectoral response. While this commitment was already growing generally in PNG, AusAID advocacy and the personal experience of individual consultants contributed.

A shift to a multisectoral approach was reflected in a series of national plans from the late 1990s (Government of PNG 1998; NAC 2004; 2006). Matching this intent, from early 2001 AusAID began actively working with contractors of existing projects across a range of sectors to promote responses to HIV. It also supported the appointment of a multisectoral advisor within its major National HIV/AIDS Support Program (NHASP) to initiate, in conjunction with the PNG National AIDS Council Secretariat (NACS), a broad range of responses across the country.

Commitment to HIV mainstreaming in different government sectors followed. While not reflected in the formal HIV/AIDS national plans, mainstreaming was informally endorsed by members of the National AIDS Council (NAC) and National AIDS Council Secretariat (NACS) from around 2004. Correspondingly, within AusAID a mainstreaming strategy was adopted for the PNG Branch in 2004, and a mainstreaming advisor was engaged in the same year to promote this approach. Because neither of the initiatives reviewed here was designed as a mainstreaming measure, they should not be judged on this basis in terms of performance. The experience of the projects, however, highlights potentials, shortfalls and continuing challenges for a mainstreaming approach.

\section{Case Studies}

\section{Royal Papua New Guinea Constabulary Development Project Phase III (2000-2005)}

This five-year project built on 12 years of Australian development assistance to the Royal Papua New Guinea Constabulary (RPNGC) with a focus on community policing, human resource management (including discipline processes), infrastructure refurbishment, and improved systems and training to enhance RPNGC capacity to analyse, prevent, investigate and prosecute crime (AusAID 2001). The project budget for Phase III was AUD 60 million.

In 2001, the project was redesigned to include an emphasis on 'integrating HIV/AIDS awareness into project activities' (see McLeod and Macintyre this volume). The redesign document acknowledged that the police community has a high HIV risk profile (see Jenkins this volume). The broader context for the 
introduction of HIV/AIDS initiatives in the Constabulary involved efforts to promote partnerships with the community, improve corporate planning, address gender bias and inequality in the police, and minimise crime against women.

\section{Activities}

The approach proposed to 'integrate' HIV into all appropriate project activities, and more generally into police training and operations. Major initiatives included the generation of a training package in conjunction with NACS. The focus was on awareness-raising and changing operational procedures. Areas covered included basic facts about HIV and AIDS; modes of transmission; relationship with other infectious diseases, particularly hepatitis; police operational contexts for HIV and AIDS, particularly cell hygiene; professional conduct; and gender issues. The package became a standard component of training for recruits. It also became the focus of dedicated in-service training and was incorporated into most other training, including community policing and decentralised training in the provinces and districts.

Other initiatives included a limited number of awareness-raising events with police families and policewomen; a review of police operational procedures to identify areas of HIV risk; promotion of linkages between the Constabulary and outside organisations also addressing HIV and AIDS such as NACS, Consultative Implementation and Monitoring Committee (CIMC) and its Family Sexual Violence Committee, Department of Health, Anglicare, and Individual and Community Rights Advocacy Forum (ICRAF) (an NGO with a gender and human rights focus); and several community theatre events that aimed to increase awareness of HIV together with other social issues.

\section{Outcomes}

The major outcome was the wide-scale incorporation of HIV issues into police training. Views of police management and consultants suggested that levels of awareness amongst police improved as a result and that police perceived a connection between their operational practice, personal behaviour and HIV and AIDS more clearly. ${ }^{3}$ This perception may have extended to the connection between gender and HIV and AIDS. Some operational practices may have altered as a result of the training, for example safer handling of detainees. There was, however, far less certainty about whether training had led to a shift in personal attitudes and behaviours of police in relation to HIV and AIDS (see McLeod and

3 Interviews conducted as part of Review of AusAID Multisectoral HIV Initiatives in Papua New Guinea (Patrick 2005) that involved senior management of RPNGC, and consultants of RPNGC Development Project Phase II and Law and Justice Sector Program. 
Macintyre this volume). Informants suggested that awareness-raising efforts among police families, particularly in the barracks, were less effective, largely due to their infrequency and didactic methods.

As a further outcome, management began taking HIV more seriously, leading to plans to develop an agency policy in response to the HIV/AIDS Management and Prevention (HAMP) Act (2003) (see Stewart this volume; McLeod and Macintyre this volume). Also discussed was the establishment of a designated coordinator position within the police based in the HR Division, to pull together and link various HIV initiatives across the agency. And a firmer basis was provided for further HIV initiatives, in peer education (supported by the EU), and awareness training in the National Capital District (supported by Save the Children Fund).

\section{Issues}

Despite progress, by the project's end a range of issues had become apparent. These included a perceived need to take HIV initiatives to a new level: to promote wider changes in attitudes, and operational and personal practice, in order to reduce HIV risk. Related needs included concern to have HIV issues better reflected in agency policy and strategy (for example in corporate plans and HR policy); stronger education on the link between HIV transmission and gender inequality; and the need to coordinate a range of HIV and AIDS activities across the agency funded by different donors and NGOs.

\section{Correctional Services Development Project Phase II (CDSP) (2000-2003)}

CSDP aimed to strengthen the operation and management of prisons (AusAID 2000). Phase II of the project was designed as an extension of earlier assistance to Correctional Services (CS) and had a major focus on 'increasing the responsiveness of the PNG justice system to community needs'. This reflected increased recognition of the inter-relationship and interdependence of many parts of the justice system in improving safety and security, and a desire to improve, ultimately, conditions for agency clients through technical assistance. The project budget for Phase II was AUD 20 million.

\section{Activities}

In contrast to the original design, Phase II of CSDP included specific HIV initiatives, one output of which was increased HIV awareness among staff, their families and detainees (see Law this volume). Major HIV-related activities included strategy development and training. The CS HIV/AIDS and Other Infectious Diseases Strategy (September 2001) was developed in close collaboration with NACS and included measures relating to human resources, 
education, prevention, treatment, counselling, testing and care for people living with HIV (PLHIV), and support for affected families. The strategy was distributed to all PNG government agencies as a model.

Training courses for staff and a small number of long-term detainees operated in 2001 and 2002. It was intended that the trainees would in turn lead awarenessraising activities in institutions. Training was developed in conjunction with NACS. Minor activities included preparation of a poster and distribution of other materials for display in institutions; a poster competition amongst detainees; and display of HIV awareness materials in prison vans.

\section{Outcomes}

The HIV/AIDS and Other Infectious Diseases Strategy represented the agency's strengthened commitment to respond to HIV, but results of implementation were inconsistent. Well-developed and enthusiastic responses occurred in some institutions, particularly larger institutions which also hosted formal training programs. In some cases, well-developed peer education programs and complementary awareness-raising sessions were mounted. Senior CS staff suggested that HIV activities may have led to better care of PLHIV in prisons and reduced stigmatisation. Support from institution commanders was essential for what was perceived as a sensitive topic. Attitudes towards the acceptability of condom distribution in institutions, for example, differed widely. Regrettably, staff families received little of the attention intended for them.

The initiatives implemented with support from CSDP provided a firmer basis for several subsequent initiatives with other donors or projects. These included a trial Peer Education project (EU), awareness-raising sessions by Anglicare (involving PLHIV) within all correctional institutions and surrounding communities, and activities under the Tingim Laip project (Elder 2009).

\section{Issues}

The need to translate aspects of the CS HIV/AIDS and Other Infectious Diseases Strategy into other areas of agency policy-making, particularly HR, and better implement the strategy became clear. Broader structural constraints within the agency-concerning resources, systems for monitoring and support, and developed management systems-hampered implementation. Subsequently initiatives have been introduced within CS to improve linkages between the centre and correctional institutions.

Unfortunately resources were inadequate for in-service training to reinforce HIV awareness and commitment, though an officer in CS who had a part-time, but dedicated responsibility for HIV and AIDS was valuable in stimulating concern. Historically, efforts to address HIV within the agency show a pattern of activity 
followed by subsidence, corresponding to receipt of donor funding. The lapse into relative inactivity reflects a lack of resources and stimulus by technical assistance, but also broader issues of competing priorities for management.

\section{Assessment of Projects against Mainstreaming Principles}

Both initiatives educated staff and raised commitment to respond to HIV within their respective institutions. Both also reflected the intrinsic value of a multisectoral approach through increasing the level of coverage and range of contexts in which HIV and AIDS are addressed. In general, however, the projects did not support a shift in their organisations' core business. Such a shift is fundamental to the mainstreaming approach. Rather, HIV was integrated into existing activities. The following analysis assesses the two initiatives against the principles of good practice in mainstreaming.

\section{Responses are Strategic and Coordinated}

The initiatives reviewed here were consistent with the support of national plans for a multisectoral approach to HIV and AIDS (Government of PNG 1998; NAC 2004, 2006). The CS attempted to align its HIV/AIDS and Other Infectious Diseases Strategy to national priorities, and both implementing organisations received material resources and developed training courses with assistance from the National AIDS Council. Yet, as suggested by key stakeholders in both implementing agencies, there appeared to be considerable potential for NAC to strengthen its coordinating and leadership role, by advising on the fit between organisational plans and national policy/strategy and facilitating partnerships between implementing and resource organisations.

\section{Responses are Based on a Sector's/Organisation's Comparative Advantage}

A mainstreaming approach based on comparative advantage requires a sector/ organisation to analyse its relationship and responsibility with regard to HIV and AIDS, and then define its most appropriate strategy. Modification or refinement of core functions, missions, objectives and programs may follow, in contrast to simply 'adding on' separate HIV components to existing programs. The generation by the CS of HIV/AIDS and Other Infectious Diseases Strategy came closest to this kind of approach, but to strengthen it, more was still needed from central planning functions within the CS, including its corporate plan and 
budget. For the Constabulary, undertaking a strategic analysis of its relationship to HIV and AIDS and identifying appropriate responses remained tasks for the future (see McLeod and Macintyre this volume).

\section{Responses Occur in both the Internal and External Domains}

The main strength and focus of the two initiatives was within the internal domain: staff education. The work of CS came closest to the best practice of acting in both internal and external domains by also educating its clients about HIV through staff and peer education. Consolidating this approach would involve a more explicit and detailed analysis of the range of HIV risks that detainees experience, within and outside correctional institutions, and developing appropriate responses to these contexts (see Law this volume). This would include preparation for release. For the Constabulary, the training programs emphasised personal protection of police, safe operational practices (such as in handling of bleeding detainees), and also warned against police engaging in unlawful assault and opportunistic sexual behaviour (see Jenkins this volume; McLeod and Macintyre this volume). As with CS, attempts to alter police behaviour and improve the quality of engagement with clients require a range of measures that extend well beyond training. These include attention to management, discipline and supervision, and direct learning from the community regarding concerns about HIV and AIDS.

In order to broaden organisational responses to HIV, the development and promotion of an organisational model for mainstreaming, adaptable to different contexts and needs, could cover areas such as training, policy and strategy development, developing service linkages and partnerships, and developing detailed implementation plans.

\section{Reponses Promote Appropriate Capacity-building}

Both projects involved capacity-building, introducing new awareness and commitment, and particularly in CS, new approaches to addressing HIV and AIDS. Achievements in building 'understanding' amongst staff were, however, limited to awareness-raising about the epidemic, how HIV is transferred, and personal protection measures. A broader challenge is to assist staff to develop analytical and planning abilities so that they can see the relevance of what they do in their daily work to the epidemic. This remains a challenge in both institutions, and more broadly across the law and justice sector. 


\section{Responses Address Other Cross-Cutting Issues: particularly Gender, Participation and Sustainability}

While concepts of gender have generally been central to responses to HIV (see Eves this volume) and the Constabulary, with support from the RPNGC Development Project, introduced gender elements into training of police officers (see McLeod and Macintyre this volume), overall, the primary concern of training in both projects related to HIV risk and personal protection from a medical and/ or behavioural perspective. This tends to downplay the importance of broader social determinants of HIV, such as endemic gender violence and women's lack of power (see Eves this volume). The HIV/AIDS and Other Infectious Diseases Strategy developed by CS did contain some gender-sensitive initiatives such as recognition of the protection needs of female detainees. Overall, however, the initiatives showed limited appreciation of the connection between HIV and gender inequality and a need for explicit gender analysis in the design of HIV initiatives was highlighted.

The CS initiative demonstrated a participatory approach. The department sought to build support amongst staff and management through generation of its HIV/ AIDS and Other Infectious Diseases Strategy. The success of the integration of HIV training with the Constabulary relied on efforts to work closely with the training section as a whole and build the initiative into on-going work plans. A broader challenge in both implementing organisations is to build participation and coordination between different sections undertaking HIV-related work. The achievements of CS, albeit limited, in involving long-term detainees as peer trainers, reinforced the effectiveness of HIV initiatives and provided a basis on which to build. Both agencies also attempted to involve a broader group of stakeholders in awareness-building, particularly staff families who commonly reside in compounds surrounding institutions. While this outreach was limited, further extension promised to reinforce the value of educational work with staff.

Efforts to build staff participation and develop strategies to guide and legitimatise initiatives were perceived by stakeholders as reinforcing sustainability. The HIV/AIDS and Other Infectious Diseases Strategy in Correctional Services, for example, was seen as continuing to provide impetus for the HIV response within the agency. A tendency for HIV initiatives to wane with the cessation of direct donor and advisor support was noted. This trend highlights the need to reinforce the status of HIV in corporate and annual agency plans, and to seek core support in sector budgets. 


\section{Conclusion}

This analysis of responses to HIV and AIDS in PNG, and specifically within two law and justice agencies, highlights a phase in the evolution of the sector's commitment and skills to respond to HIV - a sector that has potential to contribute vitally to the national response.

PNG's epidemic has been described as both generalised and concentrated. While mainstreaming promotes a systemic response that is particularly valuable for countries experiencing a generalised epidemic (AusAID 2009; UNAIDS 2004, 2), it also leverages the advantages that organisations, such as CS and RPNGC, have to influence the potentially concentrated epidemiological dynamics related to prisons, sex work and gender violence. Mainstreaming enables organisations to strengthen the ways in which they help reduce susceptibility to HIV infection among themselves and among the people they serve and implies that they too identify and minimise unintended negative effects of their own work.

The demand to mainstream HIV places additional strains upon public sector organisations in developing countries such as PNG that commonly have weak capacity and a poor service orientation. It may be regarded, however, as a preemptive step that addresses the underlying susceptibility and vulnerability of communities to infection (UNAIDS 2004). Experience in African countries highlights how the challenges of doing so are compounded in the context of epidemics which have progressed to higher level of HIV prevalence.

The good practice principles identified in this paper, although validated in the international literature, taken as whole do however represent a somewhat idealised response. Developing a mainstreaming approach in countries such as PNG is an incremental process requiring capacity-building within implementing organisations and clear starting points (UNAIDS and GTZ 2002). International experience suggests that organisations most effectively commence mainstreaming by promoting HIV awareness, knowledge and commitment among staff. Beginning with prevention activities, and in particular awareness raising and condom distribution (Elsey and Kutengule 2003), organisations then commonly undertake further and more ambitious planning, particularly in the external domain. Such a trend is suggested by the two case studies examined in this paper. As Butcher has stressed, 'Mainstreaming does not replace the need for AIDS work' (Butcher 2006, 5), such as awareness-raising, condom distribution and medical provision. Such work absorbs the bulk of AusAID funding, and is complementary to mainstreaming and is some senses a prerequisite.

The adoption of mainstreaming relies on developing a clear understanding of the meaning, intent and scope of the approach and its applicability to various organisations. This is likely to involve the incorporation and extension of 
initiatives such as those reviewed here within what will be a broader and more ambitious approach. A key aspect of this change will be for implementing organisations to move beyond 'integration'. Adding elements such as HIV training or curriculum development makes a start. The broader challenge is for organisations to assess their connection with the epidemic, identify their responsibilities, and delineate their responses in relationship to their core mandate. A mainstreaming response assists organisations to look outside their immediate institutional concerns and examine how they can assist in reducing levels of risk and vulnerability to HIV in populations with whom they work.

In the case of the law and justice sector, these issues are more obviously immediate and pertinent than in many other sectors. Safety and security in community settings, vulnerability of women, knowledge of legal rights and access to justice for marginalised people bear directly on the spread of HIV and the impacts of AIDS (see Luker and Dinnen, this volume). A significant enabling factor for mainstreaming in this sector will be access to viable methodologies, associated analytical tools and expertise. Donors such as AusAID play a role in this respect, but effective national leadership and coordination remain the basic, necessary precondition.

\section{References}

AusAID. 2000. Correctional Services Development Project-Phase II Extension Design Document. Port Moresby: AusAID.

AusAID. 2001. Royal PNG Constabulary Development Project Phase III Scope of Services. Port Moresby: AusAID.

AusAID. 2009. Intensifying the Response: Halting the Spread of HIV: Australia's International Development Strategy for HIV. Canberra: AusAID.

AusAID. 2006. Responding to HIV/AIDS in Papua New Guinea: Australia's Strategy to Support Papua New Guinea 2006-10. Canberra: AusAID.

Butcher, Kate. 2006. Mainstreaming HIV into AusAID's development portfolio in Papua New Guinea. Canberra: AusAID.

Elder, John. 2009. Tingim Paip: Success Stories from Papua New Guinea. [no place of publication stated] Family Health International.

Elsey, H. and P. Kutengule. 2003. HIV/AIDS Mainstreaming: A Definition, Some Experiences and Strategies. HIV-AIDS-STI Knowledge Programme and HERD. South Africa: University of Natal. http://gametlibrary.worldbank.org/FILES/454_ HIV\%20mainstreaming\%20experiences.pdf (accessed 27 April 2010). 
Government of PNG. 1998. Papua New Guinea National HIV/AIDS Medium Term Plan 1998 - 2002. Port Moresby: Government of PNG.

NAC (Papua New Guinea National AIDS Council). 2004. Papua New Guinea National Strategic Plan on HIV/AIDS 2004-2008. Port Moresby: National AIDS Council.

NAC (Papua New Guinea National AIDS Council). 2006. Papua New Guinea National Strategic Plan on HIV/AIDS 2006-2010. Port Moresby: National AIDS Council.

Patrick, I. 2005. Review of AusAID Multisectoral HIV Initiatives in Papua New Guinea. Canberra: AusAID.

SDC (Swiss Agency for Development Cooperation). 2004. Mainstreaming HIV/AIDS in Practice. Berne: SDC. http://www.deza.ch/ressources/deza_ product_en_1280.pdf (accessed 27 April 2010).

UNAIDS. 2003. Progress Report on the Global Response to the HIV/AIDS Epidemic (Follow-up to the 2001 United Nations General Assembly Special Session on HIV/AIDS). Geneva: UNAIDS. http://data.unaids.org/TOPICS/UNGASS2003/ UNGASS_Report_2003_en.pdf (accessed 27 April 2010).

UNAIDS. 2004. Support to Mainstreaming AIDS in Development. UNAIDS Secretariat Strategy Note and Action Framework 2004-2005. Geneva: UNAIDS. http://www. afronets.org/files/MS\%20Strategy\%20Note.pdf(accessed 27 April 2010).

UNAIDS and World Bank. 2001. AIDS, Poverty Reduction and Debt Relief: A Toolkit for Mainstreaming HIV/AIDS into Development Instruments. Geneva: UNAIDS. http:// data.unaids.org/Publications/IRC-pub02/JC536-Toolkit_en.pdf (accessed 27 April 2010).

UNAIDS and GTZ. 2002. Mainstreaming HIV/AIDS: A Conceptual Framework and Implementing Principles. Accra, Ghana: UNAIDS. http://www.afronets. org/files/mainstream.pdf (accessed 27 April 2010).

UNDP. 2002. Conceptual Shifts for Sound Planning. Towards an Integrated Approach to HIV/AIDS and Poverty. Pretoria: UNDP. http://www.sarpn. org.za/documents/d0000130/Conseptual_shifts_for_sound_plannig.pdf (accessed 27 April 2010).

United Nations. 2001. Declaration of Commitment on HIV/AIDS. United Nations Assembly Special Session on HIV/AIDS 25-27 June 2001, Geneva: United Nations.

Wilkins, Marissa and Dolar Vasani. 2002. Mainstreaming HIV/AIDS: Looking Beyond Awareness. VSO Experience in Focus series. London: Voluntary Service Overseas. 